\title{
From normal to pathological hemostasis
}

\author{
[De l'hémostase normale à l'hémostase pathologique]
}

Dominique Lasne PhD, ${ }^{*}$ Brigitte Jude MD PhD,$\dagger$ Sophie Susen MD PhD $\dagger$

Purpose: To review the evolution of knowledge on physiological hemostasis and the main abnormalities that may interfere with hemostasis in the perioperative period.

Methods: Narrative review of the literature, including relevant papers published in English.

Principal findings: Physiological hemostasis controls blood fluidity and rapidly induces hemostatic plug formation in order to stop or limit bleeding. The three distinct phases of the hemostatic process, primary hemostasis, coagulation and fibrinolysis are closely linked to each other and precisely regulated in order to efficiently close vessel wounds, promote vascular healing and maintain vessel patency. Primary hemostasis is the result of complex interactions between the vascular wall, platelets and adhesive proteins. Initiation of the coagulation pathway in vivo is secondary to the exposure of tissue factor (TF) and the formation of TF/VIla complex which can activate both FIX and FX. This initiation phase is followed by a propagation phase with amplification of thrombin generation. Several control mechanisms exist for localizing fibrin formation to the site of injury including tissue factor pathway inhibitor, protein $C$ system, antithrombin, and glycosaminoglycans on the vessel wall. Fibrinolysis is also a highly regulated system that controls fibrin dissolution. Both constitutive and acquired hemostasic defects exist. The consequences of these abnormalities are highly variable according to the type of defect, and to the genetic and environmental background.

Conclusion: Hemostasis is one of the most complex physiological self-defence systems, not only involved in control of blood fluidity but also interfering in major physiopathological processes. The evolution of our knowledge of the physiology of hemostasis has numerous implications for therapy.

Objectif: Revoir l'évolution des connaissances sur l'hémostase physiologique et les principales anomalies qui peuvent nuire à l'hémostase périopératoire.

Méthode: Une revue documentaire traditionnelle, dont les articles pertinents publiés en anglais.

Constatations principales : L'hémostase physiologique contrôle la fluidité du sang et induit rapidement la formation d'un caillot hémostatique pour stopper ou limiter l'hémorragie. Les trois phases distinctes du processus hémostatique, l'hémostase primaire, la coagulation et la fibrinolyse, sont intimement liées entre elles et précisément réglées pour fermer efficacement les blessures vasculaires, activer la cicatrisation et maintenir la perméabilité vasculaire. L'hémostase primaire est le résultat d'interactions complexes entre la paroi vasculaire, les plaquettes et les protéines adhésives. Le déclenchement du processus de coagulation in vivo est secondaire à l'exposition du facteur tissulaire (FT) et à la formation du complexe FT/VIla qui peut activer les facteurs IX et $X$. Cette phase initiale est suivie d'une phase de propagation avec amplification de la génération de thrombine. Des mécanismes de contrôle existent pour localiser la formation de fibrine au site de la lésion (l'inhibiteur du mécanisme du facteur tissulaire, le système de protéine C, l'antithrombine et les glycosaminoglycanes sur la paroi vasculaire). La fibrinolyse est aussi un système très réglé qui contrôle la dissolution de la fibrine. Il existe des anomalies constitutives et acquises de l'hémostase. Leurs conséquences sont hautement variables selon le type d'anomalie et le bagage génétique et environnemental.

Conclusion: L'hémostase est l'un des systèmes physiologiques d'autodéfense le plus complexe, qui non seulement participe au contrôle de la fluidité du sang, mais aussi intervient dans les principaux processus physiopathologiques. L'évolution de nos connaissances sur la physiologie de l'hémostase a de nombreuses implications pour le traitement.

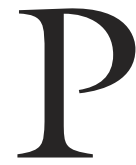
HYSIOLOGICAL hemostasis is a highly adaptative process that controls blood fluidity, and rapidly induces hemostatic plug formation after vascular injury, in order to stop or limit bleeding. After an initial triggering event, sequential steps occur, including a complex cascade of clotting factor and platelet activation. Red blood cells, leukocytes and endothelial cells are also involved in the propagation and the regulation of clot formation. The three distinct phases of the hemostatic process are pri-

From the Laboratoire d'Hématologie, ${ }^{*}$ Hôpital Necker, Paris; and the Institut d'Hématologie-Transfusion, † Centre Hospitalier Régional Universitaire Lille, Lille, France.

Address correspondence to: Dr. Dominique Lasne, Laboratoire d'hématologie, Hôpital Necker, 149 Rue de Sèvres, 75743 Paris cedex 15, France. E-mail: dom.lasne@nck.ap-hop-paris.fr 
mary hemostasis, coagulation and fibrinolysis, which are closely linked to each other and are tightly coordinated in order to efficiently close the vessel wound, promote vascular healing and maintain vessel patency. Normal hemostasis is the result of a far from stable equilibrium. Pathological situations needing surgery and anesthesia, as well as surgery or invasive procedures by themselves, acutely trigger the hemostatic system. Thus, the perioperative period is at high risk for deleterious both prohemorrhagic and prothrombotic abnormalities. This review aims to summarize current knowledge on physiological hemostasis and the main abnormalities that may interfere with hemostasis in the perioperative period.

\section{I-Primary hemostasis}

\section{I-I-Actors of primary hemostasis}

Primary hemostasis is the result of complex interactions between the vascular wall, platelets and adhesive proteins, leading to vessel wound closure by a white platelet-rich clot.

The vascular wall is lined by a continuous monolayer of endothelial cells, which controls selective exchanges between blood molecules and extravascular tissues, and play an active role in the regulation of vessel patency. ${ }^{1}$ The luminal surface of normal endothelial cells exhibits antithrombotic properties: 1) exposure of negatively charged heparin-like glycosaminoglycans and of neutral phospholipids in the external layer of the cell membrane; 2) synthesis, exposure or secretion of platelet inhibitors (prostacyclin, nitric oxide, ectoADPase), of coagulation inhibitors [thrombomodulin, protein S (PS), tissue factor (TF) pathway inhibitor and glycosaminoglycans], and of fibrinolysis activators [tissue-plasminogen activator ( $\mathrm{t}-\mathrm{PA})$ and urokinase-plasminogen activator (u-PA)]. When activated by thrombin or by aggressive stimuli such as inflammatory cytokines, endotoxin or hypoxia, the antithrombotic properties of endothelial cells convert to prothrombotic ones, characterized by exposure of anionic phospholipids on the outer leaflet of the cell membrane, secretion of platelet activating agents (platelet activating factor), exposure of coagulation factor receptors (TF, FIX and FX receptors) or cofactors $\mathrm{V}$, and secretion of inhibitors of fibrinolysis (plasminogen activator inhibitor 1 ).

By contrast, the subendothelial layer contains highly thrombogenic components such as collagen, von Willebrand factor (vWF) and other molecules involved in platelet adhesion.

\section{PLATELETS}

Platelets are essential actors of primary hemostasis. They circulate in blood $\left(150-400 \mathrm{G} \cdot \mathrm{L}^{-1}\right)$ as discoid fragments originating from the cytoplasm of bone marrow megakaryocytes. Platelets are constituted of a complex membrane system, cytoskeletal structures (microtubules and microfilaments), and granules (dense granules, $\alpha$ granules and lysosomes). The plasmatic membrane is composed of two layers of neutral glyco and phospholipids. Phospholipids play a key role in platelet functions, as second messengers, and as cofactors for platelet procoagulant activity. Cytoskeletal structures are essential in shape changes after activation. Granules contain active components that are excreted after platelet activation (adenosine diphosphate and adenosine triphosphate from dense granules, $ß$-thromboglobulin and PFIV, vWF and growth factors from $\alpha$-granules). ${ }^{2}$ After liberation, these proteins play a direct role in hemostasis activation, and in the vascular healing process.

\section{ADHESIVE PROTEINS AND THEIR RECEPTORS}

The principal adhesive proteins involved in primary hemostasis are vWF and fibrinogen. von Willebrand factor is a multimeric glycoprotein (GP) synthesized by endothelial cells and megakaryocytes, and the principal mediator of platelet adhesion to the injured vascular wall. ${ }^{3}$ von Willebrand factor is stored in Weibel-Pallade structures in endothelial cells and in $\alpha$-granules in megakaryocytes and platelets, and is also present in plasma $\left(5-10 \mu \mathrm{g} \cdot \mathrm{mL}^{-1}\right)$. The von Willebrand factor participates in fibrin clot formation through bearing and stabilization of blood coagulation FVIII (antihemophilic A factor). von Willebrand factor is a very high molecular weight GP $(0.5-20$ million $\mathrm{kDa}$ ), composed of various molecular weight subunits linked to each other by disulfur bridges. After secretion by endothelial cells, high molecular weight multimers of vWF are cleaved into lower molecular weight subunits by a specific plasma metalloproteinase, a disintegrin and metalloprotease with thrombospondin motif (ADAMTS-13). ${ }^{4}$ High molecular weight vWF can also bind to collagen and to its main platelet receptor on non-activated platelet membrane, GPIb-IX leading to platelet adhesion.

In contrast, fibrinogen binds to GPIIb-IIIa receptors on the activated platelet membrane and acts as a bridge between platelets, leading to platelet aggregation. Platelet activation increases membrane expression of GPIIb-IIIa and induces a conformational change which makes platelets able to bind plasma proteins such as fibrinogen, vWF, and fibronectin. ${ }^{5}$ Given its important plasma concentration and its high affinity 
for activated GPIIb-IIIa, fibrinogen is the main in vivo ligand of GPIIb-IIIa. Fibrinogen-GPIIb-IIIa interactions involve a three amino-acid (RGD) sequence in the fibrinogen $A \alpha$ chain.

\section{I-2-Physiology of primary hemostasis}

The first response to vascular injury is muscular contraction of the vessel wall. At the same time, platelets adhere to the subendothelial matrix, spread and undergo successive activation steps, which are linked to each other by self-amplifying positive feed-backs. ${ }^{6}$

Platelets can adhere to various substrates such as subendothelial collagen exposed to flowing blood, fibrin, and atherosclerotic material. The underlying mechanism is critically dependent of shear stress conditions. Under high shear stress conditions (in arteries and micro vessels), platelet adhesion is mostly mediated by high molecular weight forms of vWF, which bind to collagen and also to platelet GPIb-IX receptors. Noteworthy, high shear stress induces vWF conformational changes, leading to exposure of proteolysis sites for a disintegrin and metalloprotease with thrombospondin motif. This autoregulating process of platelet adhesion is essential to maintain capillary patency. In large vessels, shear stress is lower and platelet adhesion is mediated by direct platelet interaction with collagen.

Platelet adhesion is rapidly followed by reversible morphological modifications, before secretion and aggregation. Discoid platelets become spherical, pseudopodia appear, granules are centralized and come into contact with the membrane invaginations, leading to the secretion of active substances that amplify the process by increasing platelet adhesion and aggregation (adenosine diphosphate, vWF, fibrinogen, thrombospondin), participate to plasma coagulation (FV, fibrinogen), increase vascular tone and vascular contraction (serotonin), and increase cell proliferation and migration (platelet-derived growth factor or PDGF). Platelet secretion can be monitored by the dosage of specific granule products or by measurement of the expression of granule markers on the platelet surface such as P-selectin, which reflects $\alpha$-granule secretion. Platelets also synthesize pharmacologically active molecules such as thromboxane A2 and platelet activating factor. These substances can bind to specific receptors on other platelet membranes, leading to new platelet recruitment. One essential process is exposure and activation of GPIIb-IIIa receptors, which bind fibrinogen and form bridges between adjacent platelets, leading to final platelet aggregation. ${ }^{6}$ At the same time, platelet membrane phospholipids translocate, leading to exposition of negatively charged phosphatidyl serine at the outer part of the membrane. Phosphatidyl serine forms a critical catalytic surface for coagulation factor activity. ${ }^{7}$ Accumulation of phosphatidyl serine also induces emission of microvesicles which probably play a major role in disseminating platelet procoagulant activity. ${ }^{8}$

\section{I-3-Disorders of primary hemostasis}

Both constitutive and acquired defects of primary hemostasis preferentially induce sc or mucosal bleeding, appearing spontaneously or after minimal trauma. Platelet and vWF abnormalities are the most frequent.

\section{I-3-1-Trombocytopenia}

Thrombocytopenia can be associated with specific pathological situations such as autoimmune pathology, splenomegaly, and hepatic cirrhosis. In the latter situation, thrombocytopenia is related to splenomegaly and also to decreased synthesis of thrombopoietin by liver. ${ }^{9}$ Thrombocytopenia also occurs in sepsis, as a result of large tissue wounds, malignancies and obstetrical complications, and must be diagnosed rapidly, 1) as an important marker of severe illness and 2) in order to adapt substitutive or etiologic therapy when needed. Thrombocytopenia is frequent in intensive care units. ${ }^{10}$ Immunoallergic thrombocytopenia has been reported as a complication of various treatments. ${ }^{11}$ Importantly, some forms of thrombocytopenia such as heparin induced-thrombocytopenia, or antiphospholipid associated-thrombocytopenia incur a thrombotic, not a bleeding risk. ${ }^{12}$

The most frequent non-malignant hematological cause of thrombocytopenia is autoimmune thrombocytopenia, due to autoantibodies against various constituents of the platelet membrane and leading to platelet activation, aggregation, and elimination by the spleen. Infrequently, autoimmune antibodies are directed specifically against a platelet receptor, inducing acquired Glanzman thrombasthenia (anti GPIIbIIIa) or Bernard-Soulier syndrome (anti GPIb). A viral origin is suspected in many cases. ${ }^{13}$

When thrombocytopenia is associated with leukocyte and hemoglobin decrease or red blood cell abnormalities, a medullar origin (hematological malignancy or bone marrow aplasia) has to be ruled out by bone marrow examination (especially in the absence of splenomegaly). Another common cause of combined abnormalities of red blood cells, leukocytes and platelets is vitamin B12 or B9 deficiency, which commonly leads to mild thrombocytopenia associated with high mean blood red cell volume. Bone marrow examination and determination of blood levels of vitamin B9 and B12 lead to a specific diagnosis. 
TABLE Characteristics of coagulation proteins

\begin{tabular}{|c|c|c|}
\hline Coagulation factors & Properties & In vivo half-life $(\mathrm{hr})$ \\
\hline - Fibrinogen (F I) & Substrate & $100-150$ \\
\hline - FII (prothrombin) & Serin-protease zymogenVitamin K dependent & $50-120$ \\
\hline - FV (proaccelerin) & Cofactor & $12-36$ \\
\hline - FVII (proconvertin) & $\begin{array}{l}\text { Serin-protease zymogen } \\
\text { Vitamin K dependent }\end{array}$ & $4-6$ \\
\hline - FIX (anti-hemophilic B) & $\begin{array}{l}\text { Serin-protease zymogen } \\
\text { Vitamin K dependent }\end{array}$ & 24 \\
\hline - FX (F Stuart) & $\begin{array}{l}\text { Serin-protease zymogen } \\
\text { Vitamin K dependent }\end{array}$ & $36-48$ \\
\hline - FXI & Serin-protease zymogen protease & $40-80$ \\
\hline - FXII (F Hageman) & Serin-protease zymogen - contact factor & $50-70$ \\
\hline - FXIII (fibrin stabilizing factor) & Transglutaminase zymogen & $150-300$ \\
\hline - High molecular weight kininogen (F Fitzgerald) & Cofactor & 150 \\
\hline \multicolumn{3}{|l|}{ Coagulation inhibitors } \\
\hline - Antithrombin & Serpin & $50-70$ \\
\hline$-\mathrm{PC}$ & $\begin{array}{l}\text { Serin-protease zymogen } \\
\text { Vitamin K dependent }\end{array}$ & $6-8$ \\
\hline - PS & $\begin{array}{l}\text { Cofactor } \\
\text { Vitamin K dependent }\end{array}$ & $\mathrm{ND}$ \\
\hline - TFPI & Kunitz-type inhibitor & ND \\
\hline - Thrombomodulin & Receptor-cofactor & \\
\hline
\end{tabular}

$\mathrm{TF}=$ tissue factor; $\mathrm{PC}=$ protein $\mathrm{C} ; \mathrm{PS}=$ protein $\mathrm{S}$; TFPI = tissue factor pathway inhibitor; $\mathrm{ND}=$ not determined.

When thrombocytopenia is associated with a decrease of hemoglobin concentration, without any abnormality of leukocytes and red blood cells (no schizocytes), thrombocytopenia is probably the consequence, and not the cause of bleeding.

It should be noted that high platelet counts (> $600 \mathrm{G} \cdot \mathrm{L}^{-1}$ ) may also occur in perioperative situations, especially in an inflammatory context or after major bleeding, as an excessive reconstruction process, or after splenectomy. Such high platelet counts carry both thrombotic and hemorrhagic risks, particularly when associated with myeloproliferative syndromes and may need antimitotic therapy in order to achieve normal (or subnormal) platelet counts.

\section{I-3-2-Qualitative platelet abnormalities}

Rare but informative constitutive platelet membrane abnormalities, such as GPIb (Bernard-Soulier syndrome) or GPIIb-IIIa (Glanzman syndrome) deficiencies are associated to significant bleeding. ${ }^{14}$ More recently, $\alpha_{2} \beta_{1}$ integrin or GPVI deficiencies have been described, leading to an abnormal platelet response to collagen. ${ }^{15}$ Platelet granule abnormalities (storage pool deficiency) usually lead to a mild hemorrhagic syndrome. ${ }^{16}$ Other platelet abnormalities could be involved in susceptibility to arterial thrombosis. The naturally occurring variant
Leu/Pro 33 of GPIIIa is found in $40 \%$ of survivors after myocardial infarction, and in $19 \%$ of the general population. ${ }^{17}$ Myocardial infarction and stroke are more frequent in carriers of the $807 \mathrm{~T}$ allele of the $\alpha_{2}$ gene. $^{18}$ Other polymorphisms of GPI $\alpha$, GPIIb, and of the serotonine receptor are currently studied. ${ }^{14}$ The GPIIbIIIa complex plays an important role in hemostasis, as demonstrated by the high efficiency of monoclonal anti GPIIb-IIIa treatment in coronary syndromes. ${ }^{19}$

However, the most frequently encountered platelet abnormalities are those induced by widely used antiplatelet agents: acetylsalicylic acid that irreversibly inhibits thromboxane $\mathrm{A}_{2}$ synthesis, and clopidogrel that inhibits adenosine diphosphate-dependent platelet activation.

\section{I-3-3-von Willebrand's disease}

von Willebrand's disease (vWD) is the most frequent constitutive hemorrhagic disorder ( $1 \%$ of the general population). This syndrome is defined as a quantitative or qualitative vWF deficiency. Genetic transmission is dominant and is not gender-related. Clinical presentation is highly variable, even within the same family. Most patients present with partial quantitative deficiency (type $1 \mathrm{vWD}$ ). Qualitative variants (type 2 vWD) are highly heterogenous. Complete deficiency 


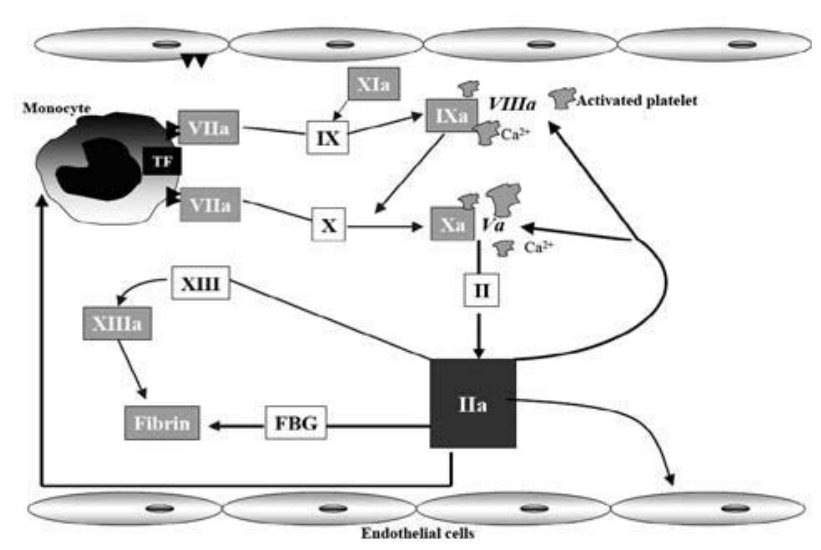

FIGURE 1 Activation of coagulation. TF $=$ tissue factor, $\mathrm{FBG}=$ fibrinogen, $\mathrm{II} a=$ thrombin. See text for details.

in vWF (type $3 \mathrm{vWD}$ ) is rare and leads to severe bleeding. When vWD is suspected, full characterization of vWD is mandatory, since treatment depends on the subtype of the disease. ${ }^{20}$

Acquired vWD have been described, due to autoimmune antibodies against vWF (autoimmune diseases and lymphoproliferative syndromes $)^{21}$ or to abnormal shear stress conditions which induce a decrease of the highest molecular weight forms of vWF, especially in aortic valve stenosis. ${ }^{22}$

\section{II-Plasma coagulation}

\section{II-I-Clotting and regulating factors}

Clotting factors are synthesized mainly in the liver and circulate in the bloodstream, except TF that is found in extravascular cells (Table). Factors V, XI and XIII are also found in platelets. Most clotting factors circulate as inactive zymogens, which can undergo sequential activation leading to expression of serine-protease activity, and conversion of prothrombin to thrombin, polymerization of fibrinogen to fibrin, which forms a hemostatic plug. Some of these factors need vitamin $\mathrm{K}$ to be fully active (factors II, VII, IX and X).

Several regulating factors are also synthesized by the liver, and circulate in the bloodstream, such as antithrombin, protein C (PC), PS and TF pathway inhibitor. Proteins $\mathrm{C}$ and $\mathrm{S}$ are vitamin K-dependent proteins. Other important regulators are expressed by the endothelial cell luminal membrane: thrombomodulin and endothelial PC receptor (EPCR).

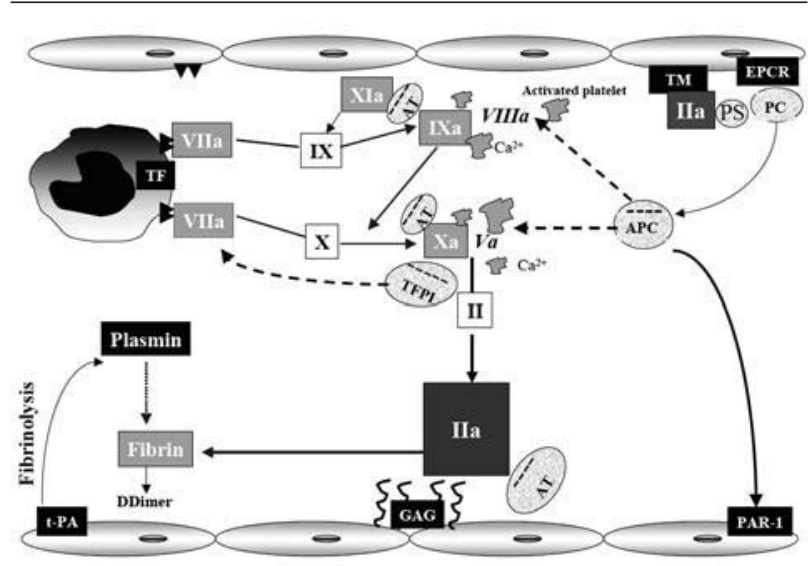

FIGURE 2 Regulation of hemostasis. TFPI = tissue factor pathway inhibitor; $\mathrm{AT}=$ antithrombin; $\mathrm{APC}=$ activated protein $\mathrm{C} ; \mathrm{EPCR}=$ endothelial protein $\mathrm{C}$ receptor; $\mathrm{TM}=$ thrombomodulin; $\mathrm{PC}=$ protein $\mathrm{C} ; \mathrm{PS}=$ protein $\mathrm{S} ; \mathrm{GAG}=$ glycosaminoglycan; PAR-1 = protease activated receptor 1 . See text for details.

\section{II-2-The physiology of coagulation}

The initiating event for coagulation activation is the exposure of TF to FVII and circulating trace amounts of FVIIa. Tissue factor exposure to flowing blood can derive from wound exposing TF expressing cells, or from aberrant TF expression by activated monocytes or endothelial cells (under septic or inflammatory stimulation), (Figure 1). ${ }^{23}$ The TF-FVIIa-complex activates FIX and FX generating low amounts of FXa (initiation phase). Trace amounts of thrombin are generated and cause back activation of FV, FVIII and FXI. Amounts of FXa sufficient to sustain clot formation occur in the presence of anionic phospholipids (provided by activated platelets) and calcium, and FVIIIa (propagation phase). Thus, antihemophilic factors (FVIII and FIX) are necessary to generate sufficient amounts of FXa and normal hemostasis.

The so-called intrinsic pathway plays a minor role in physiological hemostasis. This pathway is initiated by the contact of blood to a negatively charged surface (such as glass). It induces prekallikrein, kininogen and FXII activation, and ultimately results in the generation of FXIa. FXII, prekallikrein and kininogen deficiencies do not impair normal hemostasis. However, they induce a prolongation of the activated partial thrombin time which is currently used in European countries for pre-surgery testing and therefore can induce confusion. Of note, this pathway can interfere with fibrinolysis. ${ }^{24}$ 
Factor Xa, with phospholipids, FVa and calcium forms the prothrombinase complex, which activates prothrombin (FII) to thrombin (FIIa). Thrombin cleaves peptide links in fibrinogen $A \alpha$ and $B B$ chains of fibrinogen, inducing formation of fibrin monomers. New aminoterminal extremities of $\alpha$ (gly-pro-arg) and $B$ (gly-his-arg)-chains link to neighbouring fibrin monomers, leading to fibrin polymerization. FXIII, after activation by thrombin, stabilizes the fibrin plug by creating covalent links between fibrin monomers.

This autoamplifying coagulation system is tightly regulated by several mechanisms. Some are not specific (dilution of activated clotting factors in the blood stream, thrombin adsorption by fibrin). Among specific regulating factors, the most important is antithrombin, which can inactivate thrombin, and also FXa, FIXa, FXIa and FXIIa (Figure 2). Antithrombin forms equimolecular complexes through a reactive site that interacts with the active site of the clotting enzyme. Antithrombin can also interact with heparin and glycosaminoglycans of the vascular wall through a heparin-binding site. After binding to heparin, the inhibiting potential of antithrombin undergoes a 2,000-fold increase.

The second major regulating system of the coagulation cascade is the "thrombin, thrombomodulin, PC, and PS system". Protein C and PS are vitamin $\mathrm{K}$ dependent proteins. PC is activated by thrombin associated to its endothelial receptor, thrombomodulin. In the presence of PS as a cofactor, activated PC inactivates FVa and FVIIIa. Binding of PC to its endothelial receptor, EPCR, accelerates PC activation by the thrombin-thrombomodulin complex. ${ }^{25}$

The third known clotting factor inhibitor is TF pathway inhibitor, which inactivates the TF-FVIIa complex after formation of a quaternary complex with FXa. ${ }^{26}$

More recently, a new vitamin $\mathrm{K}$ dependent factor Xa inhibitor, protein $\mathrm{Z}$, has been described. Its physiological role remains to be determined. ${ }^{27}$

\section{II-3-Disorders of coagulation}

\section{II-3-1-BLEEDING DISORDERS}

All clotting factor deficiencies, except FXII deficiency, induce a bleeding risk. This risk is highly variable according to the type and level of the considered factor, and to the genetic and environmental background. ${ }^{28}$ Bleeding induced by clotting factor abnormalities preferentially occurs in deep connective tissues such as muscle and joints, and induces deep hematomas and hemarthrosis. In case of severe clotting factor deficien$\mathrm{cy}$, these bleeding events can be triggered by minimal trauma. The most frequent clotting factor deficiencies are hemophilia A (FVIII deficiency), and hemophilia
B (FIX deficiency). Hemophilias are X-linked recessive disorders, and thus occur only in males $(1 / 5,000$ male newborns for hemophilia A and 1/30,000 for hemophilia B). The severity of bleeding is directly dependent on the severity of FVIII or IX deficiency. Severe hemophilia is related to undetectable plasma levels of FVIII or FIX $\left(<0.01 \mathrm{U} \cdot \mathrm{L}^{-1}\right)$.

In contrast, the clinical expression of FXI and FVII deficiencies is highly variable. Severe FVII or XI deficiencies are related to homozygous or compound heterozygous genetic defects. Heterozygous defects are usually asymptomatic. Severe FXI deficiency can also be asymptomatic, perhaps because of the presence of platelet-associated FXI. Similarly, the clinical expression of severe FV deficiency depends on platelet FV level. FX and FII deficiencies are extremely rare, and their clinical expression is heterogeneous.

Fibrinogen deficiencies are rare bleeding disorders, and include total deficiency (afibrinogenemia) and partial hypofibrinogenemia, or qualitative defects (dysfibrinogenemia). Their clinical expression is highly variable. Afibrinogenemia can manifest in the perinatal period by sc hematomas or umbilical cord bleeding, but in other cases, afibrinogenemia can be relatively well tolerated, inducing only deep hematomas after significant trauma in childhood and adulthood. Dysfibrinogenemias are characterized by discordant levels of protein concentration and clotting activity, and can induce bleeding as well as thrombotic tendencies, or even be asymptomatic. ${ }^{29}$ The rare severe FXIII deficiency exhibits clinical manifestations similar to those of afibrinogenemia. Another rare coagulation disorder is Scott's disease, which consists of a platelet membrane abnormality inducing a defect in anionic phospholipids exposure, and subsequent defect in thrombin generation. ${ }^{30}$

Acquired clotting factor deficiencies are more common. They mostly arise from hepatic dysfunction (all factors will decrease, except FVIII), hemodilution, or excessive consumption during disseminated intravascular coagulation. Another typical acquired clotting factor deficiency is vitamin $\mathrm{K}$ dependent factor deficiency (FVII, FIX, FX, FII, and proteins $\mathrm{C}, \mathrm{S}, \mathrm{Z}$ ), induced either by a nutritional deficit or vitamin $\mathrm{K}$ antagonist therapy. Acquired deficiency of a single clotting factor is infrequent and secondary to specific antibodies occurring spontaneously or related to an autoimmune or lymphoproliferative disorder. Autoantibodies against FVIII are the less exceptional.

\section{II-3-2-THROMBOTIC DISORDERS}

Other constitutive or acquired coagulation disorders, usually called thrombophilia, are associated to an 
increased thrombotic risk, mostly venous thrombosis, occurring spontaneously or in high-risk situations (immobilization, treatment with oral contraceptives, pregnancy, surgery). Until 1993, only antiphospholipids (namely, lupus anticoagulant) and coagulation inhibitor deficiencies had been well identified.

Antiphospholipids are a heterogeneous family of immunoglobulin $\mathrm{G}$ and $\mathrm{M}$ (rarely $\mathrm{A}$ ), interacting with phospholipids, either directly or through interaction with proteins such as $\beta_{2}$ GPl, prothrombin or PS. Some of these antibodies act as acquired coagulation inhibitors, inducing prolongation of phospholipiddependent clotting tests, such as the activated partial thrombin time. The relationship between venous thrombosis and lupus anticoagulant is well established in patients with lupus erythematosus. ${ }^{31}$ This association remains unclear in other situations. Of note, the presence of a lupus anticoagulant is an established risk factor for arterial thrombosis and for miscarriage. ${ }^{32}$

Coagulation inhibitor deficiencies (i.e,. antithrombin, PC and PS deficiencies) are found in 5 to $10 \%$ of patients with clinical propensity to venous thromboembolism (thrombophilia). In 1993, activated PC resistance, another abnormality of the coagulation regulating system, was identified. Activated PC resistance is related to a unique mutation in the FV gene, leading to the replacement of arginine 506 by glutamine. ${ }^{33}$ This polymorphism (FV Leiden) is found in 20 to $30 \%$ of patients with thrombophilia, and only in 4 to $7 \%$ of the general population. In 1996, another frequent polymorphism of the prothrombin gene (G20210A) was shown to be present in 8 to $10 \%$ of patients with thrombophilia and only in $2 \%$ of the general population. ${ }^{34}$ Heterozygous FV Leiden and FII G20210A transition induce increased thrombin generation through decreased FVa inactivation by activated PC and increase plasma levels of FII respectively.

Clinical manifestations of these inherited thrombophilic disorders occur earlier and are more severe in patients with homozygous or combined genetic abnormalities than in heterozygous subjects. High (> 150\%) FVIII, FIX and FXI levels have also been described recently as thrombotic risk factors, but data are clearly confirmed only for FVIII. ${ }^{35}$

\section{II-3-3-COAGULATION AND INFLAMMATION}

Systemic inflammation is a risk factor for thrombosis. ${ }^{36}$ Increased plasma levels of fibrinogen and of several other factors such as FVIII and FV contribute to increased thrombin generation and fibrin deposition. Moreover, endothelial cell and monocyte TF expression is up regulated by inflammatory cytokines [tumour necrosis factor (TNF) $\alpha$, interleukin-lß], as well as in atherosclerotic plaques. ${ }^{37,38}$ Tissue factor expression by monocytes is a key event in sepsis and disseminated intravascular coagulation (DIC). ${ }^{39}$ In animal models, FVIIa antagonists can prevent sepsis associated DIC. ${ }^{40}$ Moreover, cytokine inhibitors can prevent TF-induced DIC. ${ }^{41}$ Cell membrane TF expression facilitates interaction between inflammatory cells, platelets and activated endothelial cells through P-selectin expression by platelets and endothelial cells and its ligand P-selectin GP ligand-1 on the surface of granulocytes and monocytes. ${ }^{42}$ Platelet deposition related to local inflammation probably contributes to post-angioplasty restenosis. ${ }^{43} \mathrm{P}$-selectin mediates platelet/leukocyte interactions in the thrombus, thus playing an important role in thrombus growth and stabilization. P-selectin is rapidly cleaved from the platelet surface and plasma P-selectin levels could be an interesting marker for platelet activation. ${ }^{44}$ Thrombin also activates endothelial cells and granulocytes, thus contributing to amplification of the inflammatory response. The inflammatory process includes a negative regulation of plasma coagulation inhibitors, especially PC-mediated regulation. ${ }^{45}$ Thrombomodulin and EPCR are down regulated by inflammatory cytokines such as $\mathrm{TNF} \alpha .{ }^{46}$ Elastase originating from neutrophil polymorphonuclear cells cleaves endothelial thrombomodulin, thus inducing a decrease of PC activation. ${ }^{47}$ In septic shock, activated PC infusion improves prognosis. ${ }^{48}$

In addition, hemostatic proteins and enzymes generated after activation of the hemostatic system not only induce the formation of a hemostatic plug, but also interfere in several major physiopathological processes, as recently demonstrated in transgenic animal models. Several cell receptors for hemostatic factors have been identified recently. Thrombin, FXa, the TF-FVIIa complex activate protease-activated receptors (protease-activated receptor family), which play a pivotal role in embryogenesis, vasculogenesis, angiogenesis and neuronal signalling. ${ }^{49,50}$ Activated PC also interferes with protease-activated receptor activation through interaction with EPCR. ${ }^{51}$

\section{III-Fibrinolysis}

\section{III-1-Physiological fibrinolysis}

Fibrinolysis is the enzymatic process leading to fibrin clot solubilization by plasmin originating from fibrin bound plasminogen (Figure 2). ${ }^{24}$ Plasminogen is synthesized by hepatocytes and has a high affinity for fibrin, through peptidic loops called "kringles". Plasmin is generated by cleavage of a peptide bond by plasminogen activators. The principal plasminogen activator is t-PA, which also exhibits two kringle loops 
with a high affinity for fibrin. Tissue-plasminogen activator is synthesized mainly by endothelial cells, and is secreted locally after stimulation of the endothelium by histamine, adrenalin, thrombin, FXa, and hypoxia. The second plasminogen activator is urokinase-plasminogen activator, synthesized by numerous cell types including fibroblasts, epithelial cells, and the placenta. The native form of $\mathrm{u}-\mathrm{PA}$ is prourokinase, a one chain protein, which is turned into a two-chain protein by plasmin. Contact factors (FXII, prekallikrein and kininogen) can also activate prourokinase. Urokinase-plasminogen activator plays a minor role in physiological fibrinolysis.

Plasmin generation by t-PA is controlled by a specific inhibitor, plasminogen activator inhibitor. Plasminogen activator inhibitor $\mathrm{l}$ is the most important form of plasminogen activator inhibitor, and is synthesized by endothelial cells, hepatocytes and fibroblasts. Plasminogen activator inhibitor $l$ is present in large excess in the flowing blood, and prevents inappropriate plasmin generation by forming an inactive covalent complex with t-PA and u-PA. Plasminogen activator inhibitor 1 plasma levels are increased in inflammatory states, insulin resistance syndromes and obesity. The other form of plasminogen activator inhibitor, plasminogen activator inhibitor- 2 , originates mainly from the placenta and seems to play a minor physiological role (outside pregnancy). Aberrant fibrinolysis is also prevented by circulating direct plasmin inhibitors such as $\alpha_{2}$-antiplasmin and $\alpha_{2}$-macroglobulin.

A recently described regulator of fibrinolysis is thrombin activable fibrinolysis inhibitor, which is synthesized by hepatocytes, and is able to decrease plasminogen binding to fibrin. ${ }^{52}$ Thrombin activable fibrinolysis inhibitor circulates as an inactive protein, which is activated by the thrombin-thrombomodulin complex, and then eliminates the arginine and lysine residues exposed on the surface of fibrin. Elevated levels of thrombin activable fibrinolysis inhibitor could increase the thrombotic risk. ${ }^{53}$

Proteolysis of fibrin by plasmin induces generation of fibrin degradation products. The most specific of stabilized fibrin degradation products are $\mathrm{D}$-dimers. Elevated plasma levels of D-dimers are a marker for increased thrombin formation and fibrin degradation turn-over. Plasmin is also able to proteolyze FVIII, FV, vWF and FXIII, as well as selected components of the extracellular matrix.

The fibrinolytic system is not only able to proteolyze fibrin clots, but also plays a critical role in vessel wound repair and the remodelling processes, and in angiogenesis, through degradation of the extracellular matrix.

\section{III-2-Pathological fibrinolysis}

Activation of fibrinolysis normally occurs after activation of the clotting system. During aberrant activation of coagulation such as in DIC, the fibrinolytic response may be up regulated also, contributing not only to maintenance of vessel patency but also to clot instability and increased bleeding. It should be noted that excessive fibrinolysis is often counterbalanced by increased levels of plasminogen activator inhibitor 1 during sepsis-related DIC. In rare circumstances, excessive fibrinolysis should be controlled with antifibrinolytic drugs. Excessive activation of fibrinolysis clearly may occur during cardiopulmonary bypass, which is the only circumstance, at present, where the pharmacological control of fibrinolysis has been shown to be useful. However, inhibition of fibrinolysis is but one of the mechanisms by which antifibrinolytics exert their beneficial effects during extracorporeal circulation. A detailed discussion of antifibrinolytics may be found in the section on "Pharmacological agents to reduce blood loss in the surgical patient".

\section{IV-Conclusion}

Hemostasis is one of the most complex physiological self-defence systems and is still only partially understood. Invasive procedures and surgery challenge the activating and regulating processes involved, thus limiting bleeding after surgery or trauma, but also increasing the risk of postoperative thrombosis. Several pharmacological and non pharmacological approaches are often needed in order to limit both the risk of bleeding and the risk of thrombosis.

\section{References}

1 Cines DB, Pollak ES, Buck CA, et al. Endothelial cells in physiology and in the pathophysiology of vascular disorders. Blood 1998; 91: 3527-61.

2 Rendu F, Brohard-Bohn B. The platelet release reaction: granules' constituents, secretion and functions. Platelets 2001; 12: 261-73.

3 Ruggeri $Z M$. Von Willebrand factor, platelets and endothelial cell interactions. J Thromb Haemost 2003; 1: 1335-42.

4 Kokame K, Matsumoto M, Soejima K, et al. Mutations and common polymorphisms in ADAMTS13 gene responsible for von Willebrand factor-cleaving protease activity. Proc Natl Acad Sci U S A 2002; 99: 11902-7.

5 Shattil SJ. Signaling through platelet integrin alpha IIb beta 3: inside-out, outside-in, and sideways. Thromb Haemost 1999; 82: 318-25.

6 Andrews RK, Berndt MC. Platelet physiology and thrombosis. Thromb Res 2004; 114: 447-53.

7 Heemskerk JW, Bevers EM, Lindhout T. Platelet activa- 
tion and blood coagulation. Thromb Haemost 2002; 88: 186-93.

8 Basse F, Gaffet P, Rendu F, Bienvenue A. Translocation of spin-labeled phospholipids through plasma membrane during thrombin- and ionophore A23187-induced platelet activation. Biochemistry 1993; 32: 2337-44.

9 Qian S, Fu F, Li W, Chen Q de Sauvage FJ. Primary role of the liver in thrombopoietin production shown by tissue-specific knockout. Blood 1998; 92: 2189-91.

10 Stephan F, Hollande J, Richard O, Cheffi A, MaierRedelsperger $M$, Flabault $A$. Thrombocytopenia in a surgical ICU. Chest 1999; 115: 1363-70.

11 George JN, Raskob GE, Shah SR, et al. Drug-induced thrombocytopenia: a systematic review of published case reports. Ann Intern Med 1998; 129: 886-90.

12 Chong BH. Heparin-induced thrombocytopenia. J Thromb Haemost 2003; 1: 1471-8.

13 Yenicesu I, Yetgin S, Ozyurek E, Aslan D. Virus-associated immune thrombocytopenic purpura in childhood. Pediatr Hematol Oncol 2002; 19: 433-7.

14 Clemetson KJ. Platelet glycoproteins and their role in diseases. Transfus Clin Biol 2001; 8: 155-62.

15 Nieswandt B, Watson SP. Platelet-collagen interaction: is GPVI the central receptor? Blood 2003; 102: 44961.

16 Fausett B, Silver RM. Congenital disorders of platelet function. Clin Obstet Gynecol 1999; 42: 390-405.

17 Weiss EJ, Bray PF, Tayback M, et al. A polymorphism of a platelet glycoprotein receptor as an inherited risk factor for coronary thrombosis. N Engl J Med 1996; 334: 1090-4.

18 Santoso S, Kunicki TJ, Kroll H, Haberbosch W, Gardemann A. Association of the platelet glycoprotein Ia C807T gene polymorphism with nonfatal myocardial infarction in younger patients. Blood 1999; 93: 2449-53.

19 Anonymous. Use of a monoclonal antibody directed against the platelet glycoprotein IIb/IIIa receptor in high-risk coronary angioplasty. The EPIC Investigation. N Engl J Med 1994; 330: 956-61.

20 Mannucci PM. Treatment of von Willebrand's Disease. N Engl J Med 2004; 351: 683-94.

21 Rinder MR, Richard RE, Rinder HM. Acquired von Willebrand's disease: a concise review. Am J Hematol 1997; 54: 139-45.

22 Vincentelli A, Susen S, Le Tourneau T, et al. Acquired von Willebrand syndrome in aortic stenosis. N Engl J Med 2003; 349: 343-9.

23 Mann KG. Thrombin formation. Chest 2003; 124(3 Suppl): 4S-10S.

24 Cesarman-Maus G, Hajjar KA. Molecular mechanisms of fibrinolysis. Br J Haematol 2005; 129: 307-21.

25 Taylor FB, Jr., Peer GT, Lockhart MS, Ferrell G, Esmon
CT. Endothelial cell protein C receptor plays an important role in protein $\mathrm{C}$ activation in vivo. Blood 2001; 97: 1685-8.

26 Price GC, Thompson SA, Kam PC. Tissue factor and tissue factor pathway inhibitor. Anaesthesia 2004; 59: 483-92.

27 Staton J, Sayer M, Hankey GJ, Cole V, Thom J, Eikelboom JW. Protein $\mathrm{Z}$ gene polymorphisms, protein $\mathrm{Z}$ concentrations, and ischemic stroke. Stroke 2005; 36: 1123-7.

28 Bolton-Maggs PH, Perry DJ, Chalmers EA, et al. The rare coagulation disorders--review with guidelines for management from the United Kingdom Haemophilia Centre Doctors` Organisation. Haemophilia 2004; 10: 593-628.

29 Roberts HR, Stinchcombe TE, Gabriel DA. The dysfibrinogenaemias. Br J Haematol 2001; 114: 249-57.

30 Bettache N, Gaffet P, Allegre N, et al. Impaired redistribution of aminophospholipids with distinctive cell shape change during $\mathrm{Ca} 2+$-induced activation of platelets from a patient with Scott syndrome. Br J Haematol 1998; 101: 50-8.

31 Love PE, Santoro SA. Antiphospholipid antibodies: anticardiolipin and the lupus anticoagulant in systemic lupus erythematosus (SLE) and in non-SLE disorders. Prevalence and clinical significance. Ann Intern Med 1990; 112: 682-98.

32 Greaves M, Cohen H, MacHin SJ, Mackie I. Guidelines on the investigation and management of the antiphospholipid syndrome. Br J Haematol 2000; 109: 704-15.

33 Zoller B, Dablback B. Linkage between inherited resistance to activated protein $\mathrm{C}$ and factor $\mathrm{V}$ gene mutation in venous thrombosis. Lancet 1994; 343: 1536-8.

34 Poort SR, Rosendaal FR, Reitsma PH, Bertina RM. A common genetic variation in the 3 '-untranslated region of the prothrombin gene is associated with elevated plasma prothrombin levels and an increase in venous thrombosis. Blood 1996; 88: 3698-703.

35 Kyrle PA, Minar E, Hirschl M, et al. High plasma levels of factor VIII and the risk of recurrent venous thromboembolism. N Engl J Med 2000; 343: 457-62.

36 Esmon CT. Inflammation and thrombosis. J Thromb Haemost 2003; 1: 1343-8.

37 Shebuski RJ, Kilgore KS. Role of inflammatory mediators in thrombogenesis. J Pharmacol Exp Ther 2002; 300: 729-35.

38 Young JL, Libby P, Schonbeck U. Cytokines in the pathogenesis of atherosclerosis. Thromb Haemost 2002; 88: 554-67.

39 Vickers J, Russwurm S, Dobrn B, et al. Monocyte tissue factor (CDl42) and Mac-1 (CDllb) are increased in septic patients. Thromb Haemost 1998; 79: 1219-20.

40 Uchiba M, Okajima K, Murakami K, Okabe H, 
Okamoto S, Okada $\Upsilon$. Effects of plasma kallikrein specific inhibitor and active-site blocked factor VIIa on the pulmonary vascular injury induced by endotoxin in rats. Thromb Haemost 1997; 78: 1209-14.

41 Salat C, Boekstegers P, Holler E, et al. Hemostatic parameters in sepsis patients treated with anti-TNF alphamonoclonal antibodies. Shock 1996; 6: 233-7.

42 McEver RP, Cummings RD. Role of PSGL-1 binding to selectins in leukocyte recruitment. J Clin Invest 1997; 100: S97-103.

43 Hayashi S, Watanabe N, Nakazawa K, et al. Roles of $\mathrm{P}$-selectin in inflammation, neointimal formation, and vascular remodeling in balloon-injured rat carotid arteries. Circulation 2000; 102: 1710-7.

44 Gurbel PA, Kereiakes DJ, Dalesandro MR, Babr RD, O'Connor CM, Serebruany VL. Role of soluble and platelet-bound P-selectin in discriminating cardiac from noncardiac chest pain at presentation in the emergency department. Am Heart J 2000; 139: 320-8.

45 ten Cate JW, van der Poll T, Levi M, ten Cate H, van Deventer SJ. Cytokines: triggers of clinical thrombotic disease. Thromb Haemost 1997; 78: 415-9.

46 Conway EM, Rosenberg RD. Tumor necrosis factor suppresses transcription of the thrombomodulin gene in endothelial cells. Mol Cell Biol 1988; 8: 5588-92.

47 Ishii H, Uchiyama H, Kazama M. Soluble thrombomodulin antigen in conditioned medium is increased by damage of endothelial cells. Thromb Haemost 1991; 65: 618-23.

48 Bernard GR, Vincent JL, Laterre PF, et al. Efficacy and safety of recombinant human activated protein $\mathrm{C}$ for severe sepsis. N Engl J Med 2001; 344: 699-709.

49 Hou L, Howells GL, Kapas S, Macey MG. The protease-activated receptors and their cellular expression and function in blood-related cells. Br J Haematol 1998; 101: 1-9.

50 Maragoudakis ME, Tsopanoglou NE, Andriopoulou $P$. Mechanism of thrombin-induced angiogenesis. Biochem Soc Trans 2002; 30: 173-7.

51 Riewald M, Petrovan RJ, Donner A, Mueller BM, Ruf $W$. Activation of endothelial cell protease activated receptor 1 by the protein C pathway. Science 2002; 296: 1880-2.

52 Bouma BN, Mosnier LO. Thrombin activatable fibrinolysis inhibitor (TAFI) at the interface between coagulation and fibrinolysis. Pathophysiol Haemost Thromb 2003; 33: 375-81.

53 van Tilburg NH, Rosendaal FR, Bertina RM. Thrombin activatable fibrinolysis inhibitor and the risk for deep vein thrombosis. Blood 2000; 95: 2855-9. 